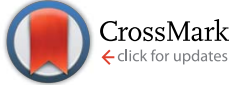

Cite this: RSC Adv., 2015, 5, 100123

\title{
Hydrothermal synthesis of rhodium-doped barium titanate nanocrystals for enhanced photocatalytic hydrogen evolution under visible light $\uparrow$
}

\begin{abstract}
Shunta Nishioka and Kazuhiko Maeda*
Rhodium-doped barium titanate $\left(\mathrm{BaTiO}_{3}: \mathrm{Rh}\right)$ nanocrystals were prepared by hydrothermal $(\mathrm{HT})$ method followed by post-heating, and examined as photocatalysts for $\mathrm{H}_{2}$ evolution from an aqueous methanol solution under visible light $(\lambda>420 \mathrm{~nm})$. The photocatalytic activity was dependent on synthetic parameters such as precursor ratio and using precursor materials, post-heating conditions, which have influence on crystallinity, compositional homogeneity and the generation of Ba defects in $\mathrm{BaTiO}_{3}: \mathrm{Rh}$, as well as the oxidation state of Rh in the material. Experimental results highlighted that suppressing the generation of $\mathrm{Ba}$ defects during the preparation process and improving the crystallinity both contributed to higher photocatalytic activity. The most active material prepared by the HT method outperformed similar analogues prepared by the polymerized complex method and a conventional solid state reaction method.
\end{abstract}

Received 28th September 2015

DOI: $10.1039 / \mathrm{c} 5 \mathrm{ra} 20044 \mathrm{j}$

www.rsc.org/advances

\section{Introduction}

Hydrogen has drawn significant attention as a clean energy carrier, which outputs high energy without releasing harmful byproducts. The development of a heterogeneous photocatalyst, which can produce $\mathrm{H}_{2}$ via water splitting with visible light, is an important topic in chemistry, and various materials including doped metal oxides, solid solutions, (oxy)nitrides and (oxy) sulfides have been developed as photocatalysts. ${ }^{1-3}$

Metal oxide photocatalysts are in general stable under irradiation, and some have achieved very high quantum yields of several tens of percent under UV irradiation. However, there are only a few metal oxides that can reduce and oxidize water under visible light. $^{2}$ Therefore, development of a visible-lightresponsive oxide photocatalyst that can produce $\mathrm{H}_{2}$ from water with visible light is of importance to construct a nonsacrificial Z-scheme water splitting system., ${ }^{2,4}$

Rh doping is one of the most effective methods that enables one to produce a visible-light-responsive photocatalyst, as reported by Kudo and co-workers. ${ }^{5}$ Our group has recently reported that Rh-doped $\mathrm{BaTiO}_{3}$ having a cubic perovskite structure prepared by solid-state reaction (SSR) method and polymerized complex (PC) method, showed photocatalytic activities for $\mathrm{H}_{2}$ evolution from water under visible light irradiation. ${ }^{6}$ The $\mathrm{BaTiO}_{3}: \mathrm{Rh}$ photocatalyst produces $\mathrm{H}_{2}$ without

Department of Chemistry, Graduate School of Science and Engineering, Tokyo Institute of Technology, 2-12-1-NE-2 Ookayama, Meguro-ku, Tokyo 152-8550, Japan. E-mail: maedak@chem.titech.ac.jp; Fax: +81-5734-2284; Tel: +81-3-5734-2239

$\dagger$ Electronic supplementary information (ESI) available: Additional characterisation and reaction data. See DOI: $10.1039 / \mathrm{c} 5 \mathrm{ra20044j}$ noticeable degradation in Z-scheme overall water splitting for as long as 30 hours. Unfortunately, however, the activity is not satisfactory, and further improvement in activity is required.

Hydrothermal (HT) method is an environmental benign, effective method for preparing perovskite materials that show high photocatalytic activity., ${ }^{7,8}$ Kominami et al. have developed a new HT synthetic method (HyCOM; hydrothermal crystallization in organic media) to obtain $\mathrm{TiO}_{2}$ nanocrystals, which exhibited very high photocatalytic activity for many kinds of reactions including $\mathrm{H}_{2} / \mathrm{O}_{2}$ evolution and the mineralization of acetic acid. ${ }^{9,10}$ Domen et al. have applied a HT method for the synthesis of $\mathrm{NaTaO}_{3}$ perovskite. ${ }^{7}$ According to that study, $\mathrm{NaTaO}_{3}$ prepared by the HT method showed higher photocatalytic activity for overall water splitting than a SSR-derived analogue. For the synthesis of a doped metal oxide, Kudo et al. recently reported that photocatalytic activity of Rh-doped $\mathrm{SrTiO}_{3}$ prepared by $\mathrm{HT}$ method for $\mathrm{H}_{2}$ evolution is comparable to that obtained by the PC method. ${ }^{8}$ While HT method has been well studied for the synthesis of various pristine metal oxides not only for photocatalytic applications but also for others, ${ }^{11}$ however, systematic investigation on the preparation parameters of a doped metal oxide has not been made so far, and the structure-activity relationship has not been clarified enough.

Base on these backgrounds, this study aimed at preparing Rh-doped $\mathrm{BaTiO}_{3}$ by a HT method under various synthesis conditions, in order to improve the photocatalytic activity for $\mathrm{H}_{2}$ evolution. The influence of synthesis parameters and postheating treatment on the photocatalytic activity is discussed on the basis of structural characterization. 


\section{Results and discussion}

\subsection{Precursor effects in the $\mathbf{H T}$ process on the formation of $\mathrm{BaTiO}_{3}: \mathrm{Rh}$}

Scheme 1 shows the preparation procedure of $\mathrm{BaTiO}_{3}: \mathrm{Rh}$ by a HT method and subsequent post-heating. The HT synthesis was conducted at $433 \mathrm{~K}$ for $42 \mathrm{~h}$ in a Teflon-lined stainless autoclave containing an aqueous suspension of $\mathrm{TiO}_{2}$ dissolved with $\mathrm{Ba}^{2+}$ and $\mathrm{Rh}^{3+}$ ions without any other additives such as surfactants. The concentration of Rh was $2.0 \mathrm{~mol} \%$ unless otherwise stated.

We first investigated effects of $\mathrm{TiO}_{2}$ precursor on the formation of $\mathrm{BaTiO}_{3}: \mathrm{Rh}$ using four different $\mathrm{TiO}_{2}$ particles, which are P25 (a mixture of anatase, rutile and amorphous $\mathrm{TiO}_{2}$ nanoparticles), ${ }^{\mathbf{1 2}}$ nanosized anatase (JRC-TIO-8), nanosized rutile (JRC-TIO-6), and submicron-size anatase (purchased from Kanto Chemicals Co.). Structural properties of these $\mathrm{TiO}_{2}$ precursors are summarized in Table 1, and typical TEM images are shown in Fig. $\mathrm{S} 1 . \dagger$

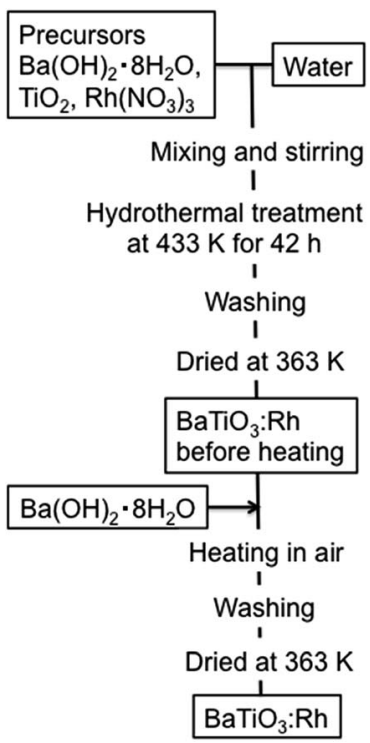

Scheme 1 Preparation scheme of $\mathrm{BaTiO}_{3}: \mathrm{Rh}$ by a hydrothermal method, followed by post-heating.

Table 1 Physicochemical properties of $\mathrm{TiO}_{2}$ used as the precursor in this work

\begin{tabular}{llll}
\hline $\mathrm{TiO}_{2}$ & $\begin{array}{l}\text { Particle } \\
\text { size/nm }\end{array}$ & $\begin{array}{l}\text { Specific surface } \\
\mathrm{area} / \mathrm{m}^{2} \mathrm{~g}^{-1}\end{array}$ & Crystal phase \\
\hline $\mathrm{P} 25$ & $10-50$ & 51 & $\begin{array}{l}\text { Mixture of anatase, } \\
\text { rutile and amorphous } \\
\text { Anatase }\end{array}$ \\
$\begin{array}{l}\text { Submicron } \\
\text { anatase } \\
\text { (Kanto }\end{array}$ & $50-120$ & 16 & Anatase \\
$\begin{array}{l}\text { Chemicals Co. }) \\
\text { Nano anatase } \\
\text { (JRC-TIO-8) }\end{array}$ & $\sim 5$ & 231 & Rutile \\
$\begin{array}{l}\text { Nano rutile } \\
\text { (JRC-TIO-6) }\end{array}$ & $30-50$ & 81 &
\end{tabular}
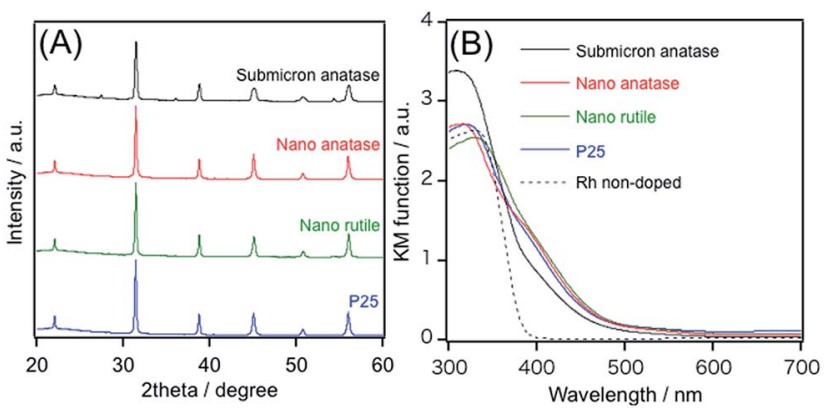

Fig. 1 (A) XRD patterns and (B) UV-visible diffuse reflectance spectra of products obtained from different $\mathrm{TiO}_{2}$ precursors without postheating. An excess amount of $\mathrm{Ba}(\mathrm{OH})_{2} \cdot 8 \mathrm{H}_{2} \mathrm{O}(10 \mathrm{~mol} \%)$ was added in the HT process.

Fig. 1A shows X-ray diffraction (XRD) patterns of products obtained from different $\mathrm{TiO}_{2}$ precursors without post-heating. A $10 \mathrm{~mol} \%$ excess barium hydroxide was added into the mixture of starting materials in all cases. All of the prepared samples, except for the sample using submicron-size anatase, showed single-phase diffraction patterns attributed to cubic perovskite $\mathrm{BaTiO}_{3}$. No significant difference with respect to FWHM and peak positions could be identified. However, in the sample prepared from submicron-size anatase, a small amount of unreacted $\mathrm{TiO}_{2}$ phase was observable.

Fig. 1B shows UV-visible diffuse reflectance spectra of the same set of the samples, along with a spectrum of undoped $\mathrm{BaTiO}_{3}$ for comparison. As reported previously, undoped $\mathrm{BaTiO}_{3}$ shows no absorption band in visible light region. ${ }^{6}$ However, the Rh-doped materials just after HT synthesis were yellow powder, exhibiting a visible light absorption band at around $500 \mathrm{~nm}$. This absorption can be assigned to $\mathrm{Rh}^{3+}$ species in $\mathrm{BaTiO}_{3}: \mathrm{Rh}^{6}{ }^{6}$ In the sample prepared from submicron-size anatase, the absorption band at $600-700 \mathrm{~nm}$, assignable to $\mathrm{Rh}^{4+}$ species, is more pronounced, and the $500 \mathrm{~nm}$ absorption band is slightly weaker compared to others. This indicates that the densities of $\mathrm{Rh}^{4+}$ and $\mathrm{Rh}^{3+}$ species in the sample prepared from submicron-size anatase are greater and smaller than those in others.
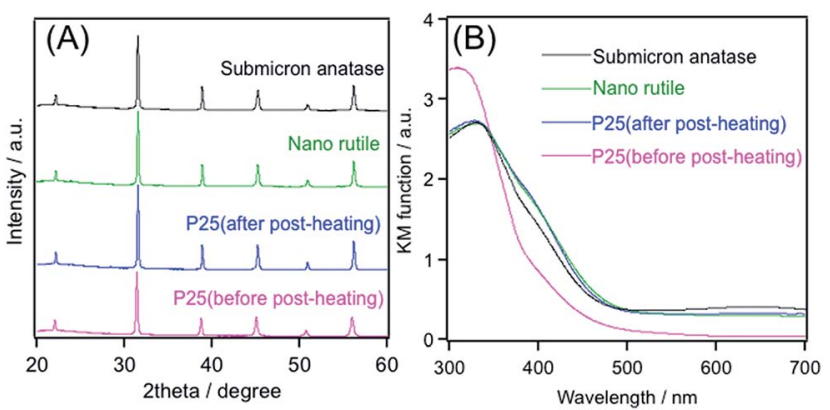

Fig. 2 (A) XRD patterns and (B) UV-visible diffuse reflectance spectra of hydrothermally synthesized $\mathrm{BaTiO}_{3}: \mathrm{Rh}$ using $\mathrm{P} 25$, nano-size rutile and submicron-size anatase, further subject to post-heating at $1173 \mathrm{~K}$. An excess amount of $\mathrm{Ba}(\mathrm{OH})_{2} \cdot 8 \mathrm{H}_{2} \mathrm{O}(10 \mathrm{~mol} \%)$ was added in the HT process. 

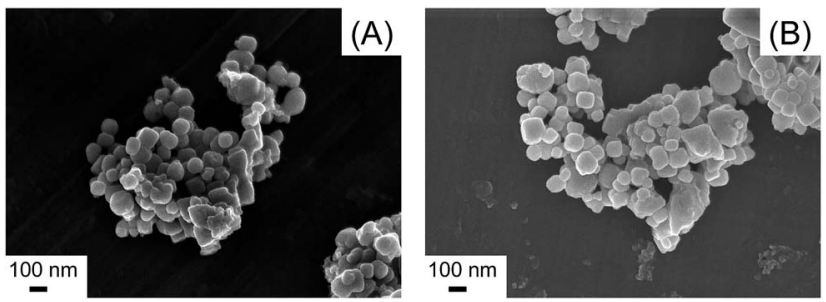

Fig. 3 SEM images of a hydrothermally synthesized $\mathrm{BaTiO}_{3}$ : Rh using $\mathrm{P} 25$ as the precursor. (A) Before and (B) after post-heating at $1173 \mathrm{~K}$.

After post-heating of a hydrothermally synthesized $\mathrm{BaTiO}_{3}$ :$\mathrm{Rh}$ in air at $1173 \mathrm{~K}$ for $7 \mathrm{~h}$, XRD patterns became stronger and narrower (Fig. 2A). This result indicates that crystallization of the product proceeds during post-heating. The crystal growth was also evident from the result of SEM observations (Fig. 3), accompanied with a decrease in the specific surface area from 8 to $4 \mathrm{~m}^{2} \mathrm{~g}^{-1}$. In addition, no noticeable difference was observed in all of the post-heated samples, as shown in Fig. 2A. However, the remaining anatase phase observed in the submicron-size anatase sample before post-heating (see Fig. 1A) disappeared completely. Fig. 2B shows diffuse reflectance spectra of the same set of the samples. Upon post-heating, absorption at longer wavelengths due to $\mathrm{Rh}^{4+}$ species was pronounced only when submicron-anatase was employed as the precursor. On the other hand, the spectral feature of samples prepared using P25 and nanosized rutile resembles each other. The details of post-heating will be described in the latter section.

\subsection{Effects of excess addition of barium hydroxide on the formation of $\mathrm{BaTiO}_{3}: \mathrm{Rh}$}

Because addition of an excess amount of $\mathrm{Ba}^{2+}$ ions in the HT process was expected to affect the production of $\mathrm{BaTiO}_{3}: \mathrm{Rh}$, we investigated this by altering the initial amount of barium hydroxide. XRD and DRS analyses showed that no noticeable difference in the HT products could be identified, even when the HT synthesis was conducted using a stoichiometric mixture (i.e., the ratio of $\mathrm{Ba} /(\mathrm{Ti}+\mathrm{Rh})=1.00)$, compared to the material prepared with an excess barium hydroxide (Fig. S2 $\dagger$ ). An exception is that the $\mathrm{Rh}^{4+}$ absorption band in the stoichiometric sample after post-heating (green line in Fig. S2†) is slightly more pronounced, compared to the excess Ba material (black line). As listed in Table 2, however, ICP-MS analysis indicated a clear difference in the chemical composition. It showed that the $\mathrm{Ba} /$ $(\mathrm{Ti}+\mathrm{Rh})$ ratio in the stoichiometric sample was 0.93 (entry 1 ), smaller than the ideal value of 1.00, while the excess Ba sample had the $\mathrm{Ba} /(\mathrm{Ti}+\mathrm{Rh}$ ) ratio of 1.00 (entry 2$)$, almost equal to unity. This means that the stoichiometric sample contained Ba defects in the crystal lattice more or less.

Post-heating of a hydrothermally synthesized metal oxide at elevated temperatures will in general result in further crystallization and/or crystal growth, which may contribute to an enhanced photocatalytic activity. ${ }^{8}$ The hydrothermally synthesized samples were then subject to post-heating in the presence of an excess amount of barium hydroxide (5.0 mol\% excess).
Table 2 Results of ICP-MS analyses ${ }^{a}$

\begin{tabular}{llll}
\hline Entry & $\begin{array}{l}\text { HT synthesis with } \\
\text { an excess } \mathrm{Ba}(\mathrm{OH})_{2}\end{array}$ & $\begin{array}{l}\text { Post-heating with } \\
\text { an excess } \mathrm{Ba}(\mathrm{OH})_{2}\end{array}$ & $\begin{array}{l}\text { The } \mathrm{Ba} /(\mathrm{Rh}+\mathrm{Ti}) \text { ratio } \\
\text { in } \mathrm{BaTiO}_{3}: \mathrm{Rh}\end{array}$ \\
\hline 1 & No & - & 0.93 \\
2 & Yes & - & 1.00 \\
3 & No & Yes & 1.00 \\
4 & Yes & Yes & 1.06 \\
5 & No & No & 0.91 \\
6 & Yes & No & 0.99
\end{tabular}

${ }^{a}$ The reproducibility of the ratio measured by ICP-MS was within $0.01-$ 0.02 . In each case, HT synthesis was made using $\mathrm{P} 25$ as the precursor in the presence of an excess $\mathrm{Ba}(\mathrm{OH})_{2} \cdot 8 \mathrm{H}_{2} \mathrm{O}(10 \mathrm{~mol} \%)$.

Again XRD measurements showed that there was no noticeable difference between the two after post-heating (Fig. S3†). Also, no noticeable change among these samples could be identified in SEM as well (Fig. S4†). However, ICP-MS analysis indicated that the $\mathrm{Ba} /(\mathrm{Ti}+\mathrm{Rh})$ ratio of the sample, which was prepared using stoichiometric precursors during HT process, was 1.00 (entry 3). It means that the $\mathrm{Ba}$ defects were compensated to a certain extent by addition of barium hydroxide in the post-heating step. For the sample prepared using excess barium hydroxide during the $\mathrm{HT}$ process, the $\mathrm{Ba} /(\mathrm{Ti}+\mathrm{Rh})$ ratio of the sample was increased from 1.00 to 1.06 , as expected. XPS measurement showed that the surface atomic ratio of $\mathrm{Ba} /(\mathrm{Ti}+\mathrm{Rh})$ was approximately 1.5 , much higher than the $\mathrm{Ba} /(\mathrm{Ti}+\mathrm{Rh})$ ratio determined by ICP-MS, meaning that Ba species are segregated in the surface region.

Without addition of an excess barium hydroxide in the postheating step, the $\mathrm{Ba} /(\mathrm{Ti}+\mathrm{Rh})$ ratio of $\mathrm{BaTiO}_{3}: \mathrm{Rh}$ tended to decrease upon post-heating at $1173 \mathrm{~K}$, regardless of whether or not an excess amount of barium hydroxide was added in the HT process (entries 5 and 6). These results suggest that postheating at elevated temperatures might generate Ba defects in $\mathrm{BaTiO}_{3}: \mathrm{Rh}$, and the addition of barium hydroxide in the postheating step can suppress the defect formation. More detailed investigation on the post-heating effect will be shown in the latter section.

\subsection{Photocatalytic activities of $\mathrm{BaTiO}_{3}: \mathrm{Rh}$ prepared using different precursors}

Then we evaluated photocatalytic activities of the synthesized materials using different precursors. For these samples, postheating was made in static air at $1173 \mathrm{~K}$ for $7 \mathrm{~h}$ in the presence of an additional barium hydroxide ( $5.0 \mathrm{~mol} \%$ excess). As mentioned later, post-heating was indispensable for obtaining high activity. As listed in Table 3, photocatalytic activity of $\mathrm{BaTiO}_{3}: \mathrm{Rh}$ depended strongly on the precursors employed in the HT process. In all cases, Pt $(0.5 \mathrm{wt} \%)$ was loaded onto $\mathrm{BaTiO}_{3}: \mathrm{Rh}$ by an in situ photodeposition method in order to promote hydrogen evolution catalysis, and it was found that $0.5 \mathrm{wt} \% \mathrm{Pt}$ loading was the best to perform the reaction. TEM observation indicated that Pt nanoparticles of 3-5 $\mathrm{nm}$ in size were distributed on the $\mathrm{BaTiO}_{3}: \mathrm{Rh}$ surface with some 
Table 3 Photocatalytic activities of $\mathrm{BaTiO}_{3}: \mathrm{Rh}$ prepared using different $\mathrm{TiO}_{2}$ precursors for $\mathrm{H}_{2}$ evolution from an aqueous methanol solution under visible light $(\lambda>420 \mathrm{~nm})^{a}$

\begin{tabular}{|c|c|c|c|c|}
\hline Entry & $\mathrm{TiO}_{2}$ & $\begin{array}{l}\text { Specific } \\
\text { surface } \\
\text { area/ } \\
\mathrm{m}^{2} \mathrm{~g}^{-1}\end{array}$ & $\begin{array}{l}\text { Ratio of } \mathrm{Ba} / \\
(\mathrm{Ti}+\mathrm{Rh}) \text { in the } \\
\text { starting mixture } \\
\text { of the HT process }\end{array}$ & $\begin{array}{l}\mathrm{H}_{2} \text { evolved } \\
(3 \mathrm{~h}) / \mu \mathrm{mol}\end{array}$ \\
\hline 1 & $\mathrm{P} 25$ & 4 & 1.10 & 42.3 \\
\hline 2 & Nano anatase & 9 & 1.10 & 38.7 \\
\hline 3 & Nano rutile & 6 & 1.10 & 18.7 \\
\hline 4 & $\begin{array}{l}\text { Submicron } \\
\text { anatase }\end{array}$ & 2 & 1.10 & 13.3 \\
\hline 5 & P25 & 4 & 1.00 & 22.0 \\
\hline
\end{tabular}

${ }^{a}$ Reaction conditions: catalyst, $100 \mathrm{mg}$ ( $0.5 \mathrm{wt} \% \mathrm{Pt}$ photodeposited in situ); 10 vol\% aqueous methanol solution $100 \mathrm{~mL}$; light source, xenon lamp $(300 \mathrm{~W})$ fitted with a cold mirror (CM-1) and a cutoff filter (L42); reaction vessel, Pyrex top-irradiation type. Post-heating was made for all of the samples at $1173 \mathrm{~K}$ for $7 \mathrm{~h}$ in the presence of an excess amount of $\mathrm{Ba}(\mathrm{OH})_{2} \cdot 8 \mathrm{H}_{2} \mathrm{O}(5.0 \mathrm{~mol} \%)$.

aggregation (Fig. S5 $\dagger$ ). Samples prepared using P25 and nanosized anatase, which consist of nanoparticulate anatase as the main phase, showed relatively high activity (entries 1 and 2). Using nanoparticulate rutile as the precursor, however, the activity was approximately half of those recorded using P25 and nanosized anatase (entry 3), even though these XRD patterns and DRS were very similar (Fig. 2). When submicron-size anatase was used as the precursor, the activity was about $30 \%$ of that recorded using P25 and nanosized anatase (entry 4). It was thus found that $\mathrm{TiO}_{2}$ that contains nanosized anatase as the main phase was better as the precursor for HT synthesis of $\mathrm{BaTiO}_{3}:$ Rh nanocrystals.

We also found that adding an excess amount of barium hydroxide in the HT process was important for activityenhancement. The activity of $\mathrm{BaTiO}_{3}: \mathrm{Rh}$ prepared using the stoichiometric amount of precursors (i.e., $\mathrm{Ba} /(\mathrm{Ti}+\mathrm{Rh})=1.00)$ in the HT process was relatively low (entry 5), even though an additional amount of barium hydroxide was supplied in the subsequent post-heating process.

\subsection{Effects of post-heating on physicochemical properties of $\mathrm{BaTiO}_{3}:$ Rh}

More detailed investigation on the HT synthesis of $\mathrm{BaTiO}_{3}: \mathrm{Rh}$ was made, focusing on the effects of post-heating temperature of the hydrothermally-synthesized $\mathrm{BaTiO}_{3}: \mathrm{Rh}$ on physicochemical and photocatalytic properties. For these investigations, an excess barium hydroxide (10 mol\%) was added in the HT process, based on the previous finding mentioned above.

Fig. 4A shows XRD patterns of $\mathrm{BaTiO}_{3}: \mathrm{Rh}$ post-heated at different temperatures in the presence of an additional barium hydroxide (5.0 mol\%). Compared to the unheated material, $\mathrm{BaTiO}_{3}: \mathrm{Rh}$ post-heated at $873 \mathrm{~K}$ exhibited sharper and more intense diffraction peaks, indicating the occurrence of crystal growth upon post-heating. However, increasing the heating temperature up to $1273 \mathrm{~K}$ did not alter the diffraction patterns. SEM observation showed that particles of the $1173 \mathrm{~K}$ sample are
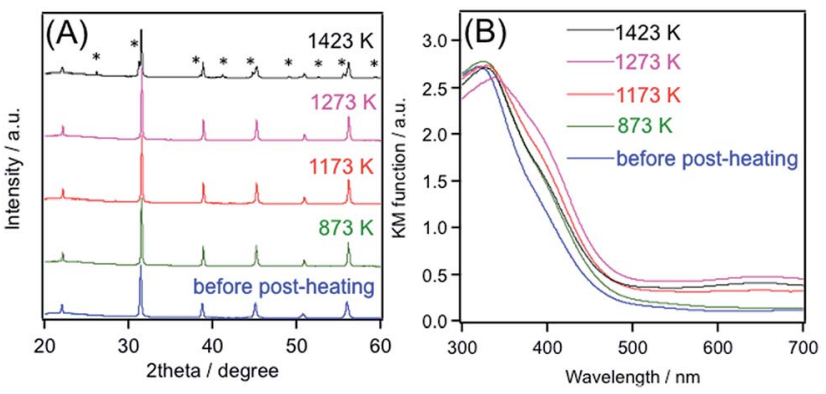

Fig. 4 (A) XRD patterns and (B) UV-visible diffuse reflectance spectra of $\mathrm{BaTiO}_{3}$ : Rh post-heated at different temperatures in the presence of an additional $\mathrm{Ba}(\mathrm{OH})_{2} \cdot 8 \mathrm{H}_{2} \mathrm{O}(5.0 \mathrm{~mol} \%)$. The star * indicates hexagonal $\mathrm{BaTiO}_{3}$

sintered to some extent to form larger secondary particles, compared to the sample just after HT treatment, as already shown in Fig. 3. This observation is consistent with the result of XRD measurement (Fig. 4A). At $1423 \mathrm{~K}$, hexagonal $\mathrm{BaTiO}_{3}$ phase was generated, accompanied with a decrease in the diffraction peak intensity of cubic $\mathrm{BaTiO}_{3}$ phase.

On the other hand, DRS underwent a successive change with increasing temperature; at elevated temperatures except for the sample at $1423 \mathrm{~K}$, absorption at longer wavelengths due to $\mathrm{Rh}^{4+}$ species was more pronounced (Fig. 4B). This would be reasonable, because heat-treatment at elevated temperatures promoted oxidation of $\mathrm{Rh}^{3+}$ into $\mathrm{Rh}^{4+}$ in $\mathrm{BaTiO}_{3}: \mathrm{Rh}$. We also tried to quantify the $\mathrm{Rh}^{4+} / \mathrm{Rh}^{3+}$ existence ratio in these samples by means of XPS. However, the position of the $\mathrm{Rh}_{3} \mathrm{~d}_{5 / 2}$ peak remained before and after post-heating (Fig. S6†), different from the result of DRS measurement (Fig. 4B). It is likely that the change in the valence state of the Rh species between the two samples was too small to be detected by XPS measurements. A similar result has been obtained in our previous study on the same material prepared by the PC method. ${ }^{6}$ In that case, the Rh3 $\mathrm{d}_{5 / 2}$ XPS peak of the as-prepared $\mathrm{BaTiO}_{3}: \mathrm{Rh}$ did not undergo a change even after hydrogen reduction treatment.

\subsection{Photocatalytic activities of post-heated $\mathrm{BaTiO}_{3}: \mathrm{Rh}$}

Table 4 lists photocatalytic activities of hydrothermally synthesized $\mathrm{BaTiO}_{3}: \mathrm{Rh}$ further post-heated at different temperatures. Here an additional amount of barium hydroxide $5.0 \mathrm{~mol} \%$ excess) was mixed with a hydrothermally synthesized $\mathrm{BaTiO}_{3}: \mathrm{Rh}$ before post-heating. The unheated sample exhibited relatively low activity (entry 1). However, the photocatalytic activity was increased with a rise of the post-heating temperature to reach a maximum at $1273 \mathrm{~K}$ (entry 4), beyond which it began to drop significantly. Interestingly, even upon post-heating at suitable temperature, we could not obtain high activity without addition of an excess barium hydroxide (entry 6).

As the result of applying HT synthesis and optimizing the synthetic parameters, we could obtain an apparent quantum yield for $\mathrm{H}_{2}$ evolution of $c a .0 .8 \%$ at $420 \mathrm{~nm}$, which was 1.5 times higher than that recorded by the PC method. ${ }^{6}$ It should be also noted that the activity of the HT sample was about an order of magnitude higher than that of the SSR sample. ${ }^{6}$ 
Table 4 Photocatalytic activities of $\mathrm{BaTiO}_{3}: \mathrm{Rh}$ post-heated at different temperatures for $\mathrm{H}_{2}$ evolution from an aqueous methanol solution under visible light $(\lambda>420 \mathrm{~nm})^{a}$

\begin{tabular}{lllll}
\hline Heating & $\begin{array}{l}\text { Addition of } 5.0 \text { mol\% } \\
\mathrm{Ba}(\mathrm{OH})_{2} \cdot 8 \mathrm{H}_{2} \mathrm{O}\end{array}$ & $\begin{array}{l}\text { Specific } \\
\text { surface } \\
\text { in the post- } \\
\text { area/ } \\
\mathrm{m}^{2} \mathrm{~g}^{-1}\end{array}$ & $\begin{array}{l}\mathrm{H}_{2} \text { evolved } \\
(3 \mathrm{~h}) / \mu \mathrm{mol}\end{array}$ \\
\hline 1 & $\mathrm{~K}$ & heating step & & \\
2 & 873 & Yes & 8 & 10.4 \\
3 & 1173 & Yes & 8 & 12.8 \\
4 & 1273 & Yes & 4 & 42.1 \\
5 & 1423 & Yes & 4 & 54.1 \\
6 & 1173 & Yes & 3 & 1.9 \\
& & No & 4 & 19.4
\end{tabular}

${ }^{a}$ Reaction conditions: catalyst, $100 \mathrm{mg}$ (0.5 wt\% Pt photodeposited in situ); 10 vol\% aqueous methanol solution $100 \mathrm{~mL}$; light source, xenon lamp $(300 \mathrm{~W})$ fitted with a cold mirror (CM-1) and a cutoff filter (L42); reaction vessel, Pyrex top-irradiation type. HT synthesis was made using $\mathrm{P} 25$ as the precursor in the presence of an excess $\mathrm{Ba}(\mathrm{OH})_{2} \cdot 8 \mathrm{H}_{2} \mathrm{O}$ (10 $\mathrm{mol} \%)$

\subsection{Factors affecting photocatalytic activity of $\mathrm{BaTiO}_{3}: \mathrm{Rh}$}

The results of photocatalytic reactions indicated that the activity of $\mathrm{BaTiO}_{3}: \mathrm{Rh}$ for $\mathrm{H}_{2}$ evolution was strongly dependent on the preparation parameters both in the HT process and in postheating step (Tables 3 and 4). In the HT process, an appropriate choice of $\mathrm{TiO}_{2}$ precursor was found to be very important to produce an active $\mathrm{BaTiO}_{3}: \mathrm{Rh}$ photocatalyst. As shown in Fig. 2, single-phase diffraction patterns assigned to a perovskite structure were observed for samples prepared using nanosized $\mathrm{TiO}_{2}$, regardless of the crystal structure (anatase or rutile). On the other hand, small peaks assigned to anatase $\mathrm{TiO}_{2}$ remained in the sample prepared using submicron anatase. Although post-heating of these samples at $1173 \mathrm{~K}$ resulted in the production of a single-phase $\mathrm{BaTiO}_{3}: \mathrm{Rh}$, it is clear that the sample prepared using larger anatase has compositional inhomogeneity, which could account for the relatively low activity of the material. It is most likely that the reactivity of larger $\mathrm{TiO}_{2}$ with other precursors of $\mathrm{Ba}$ and $\mathrm{Rh}$ in the HT process was too low to produce a single-phase perovskite material.

To support this idea, we synthesized $\mathrm{BaTiO}_{3}: \mathrm{Rh}$ in the same manner using $\mathrm{P} 25 \mathrm{TiO}_{2}$, but with different $\mathrm{Rh}$ precursors of $\mathrm{Rh}_{2} \mathrm{O}_{3}$ and $\mathrm{RhCl}_{3}$, which are respectively insoluble and soluble in water. As shown in Fig. S7, $\uparrow$ XRD analysis showed that a single phase diffraction pattern assignable to $\mathrm{BaTiO}_{3}$ was obtained when a water-soluble $\mathrm{Rh}$ precursor (i.e., $\mathrm{Rh}\left(\mathrm{NO}_{3}\right)_{3}$ and $\mathrm{RhCl}_{3}$ ) was used, while the $\mathrm{Rh}_{2} \mathrm{O}_{3}$ derived sample contained impurity phase. As expected, $\mathrm{BaTiO}_{3}$ : Rh prepared from $\mathrm{Rh}_{2} \mathrm{O}_{3}$ produced a trace amount of $\mathrm{H}_{2}$, while $\mathrm{Rh}\left(\mathrm{NO}_{3}\right)_{3}$ and $\mathrm{RhCl}_{3}$ derived ones showed appreciable activity (Fig. $\mathrm{S} 8 \dagger$ ).

It can be thus concluded that reactivity of precursors in the HT process is a critical factor that enhances the photocatalytic activity of $\mathrm{BaTiO}_{3}: \mathrm{Rh}$; in the present case, using nanosized $\mathrm{TiO}_{2}$ is essential. Interestingly, however, the activity of $\mathrm{BaTiO}_{3}: \mathrm{Rh}$ prepared using nanosized rutile $\mathrm{TiO}_{2}$ was almost half of that derived from nanosized $\mathrm{TiO}_{2}$ consisting of anatase as the main phase, even though there is almost no difference in XRD and
DRS (Fig. 2). During the formation of $\mathrm{BaTiO}_{3}: \mathrm{Rh}$ from a $\mathrm{TiO}_{2}$ aqueous suspension containing $\mathrm{Ba}^{2+}$ and $\mathrm{Rh}^{3+}$ in the HT process, it is most likely that rearrangement of constituent ions occurs because the crystal structure of $\mathrm{TiO}_{2}$ is different from that of $\mathrm{BaTiO}_{3}: \mathrm{Rh}$. ICP-MS analysis showed that the rutile derived material had the $\mathrm{Ba} /(\mathrm{Ti}+\mathrm{Rh})$ ratio of 0.96 , even though the synthesis was conducted in the presence of an excess amount of barium hydroxide both in the HT process and postheating step. This result indicates that this sample contains $\mathrm{Ba}$ defects in its structure, which is most likely to contribute to the lower photocatalytic activity. Note here that the activity was almost independent of the specific surface area.

In addition to suitable precursors for the HT synthesis, addition of an excess amount of barium hydroxide before the synthesis was essential to obtaining $\mathrm{BaTiO}_{3}: \mathrm{Rh}$ that shows higher activity. Even with addition of barium hydroxide (5.0 mol\% Ba) after the HT process (that is, just before post-heating), the activity was approximately half of those prepared with excess Ba (see Table 3). ICP-MS analyses showed that the ratio of $\mathrm{Ba} /(\mathrm{Ti}+\mathrm{Rh})$ in the HT product prepared from stoichiometric amounts of precursors was 0.93. This shortage of Ba indicates the formation of Ba defects.

In the post-heating step, both heating temperature and addition of an excess amount of barium hydroxide were important factors. The enhanced activity of $\mathrm{BaTiO}_{3}: \mathrm{Rh}$ with increasing temperature (see Table 4 and Fig. S7†) is primarily associated with the improvement in the crystallization of the material. In the temperature range up to $1273 \mathrm{~K}$, where the largest increase in activity was obtained, the XRD peak became stronger and narrower (Fig. 4A) and the particles of $\mathrm{BaTiO}_{3}: \mathrm{Rh}$ grew to some extent (Fig. 3), consistent with the change in the specific surface area. Crystallization decreases the density of defects and/or structural imperfections that can act as recombination centers between photogenerated electrons and holes, resulting in an enhanced activity. ${ }^{2,4}$ Another possible cause of the enhanced activity with temperature is the generation of suitable density of $\mathrm{Rh}^{4+}$ species, as observed in UV-visible DRS (Fig. 4B). Kudo et al. claimed that during photocatalytic $\mathrm{H}_{2}$ evolution on $\mathrm{SrTiO}_{3}: \mathrm{Rh}$, part of $\mathrm{Rh}^{4+}$ ions in the crystal lattice undergo photoreduction by electrons generated in the conduction band of the material. ${ }^{5}$ As the result, unstable $\mathrm{Rh}^{3+}$ ions, which are more effective for the $\mathrm{H}_{2}$ evolution than the stabilized $\mathrm{Rh}^{3+}$ ions by oxygen defects, are formed. However, further increase in calcination temperature resulted in a significant drop in activity (Table 4 and Fig. S7†). Although this might be due to the generation of $\mathrm{Rh}^{4+}$ species that do not undergo photoreduction, XRD data clearly indicated that the structure of cubic perovskite $\mathrm{BaTiO}_{3}: \mathrm{Rh}$ was destroyed upon heating at $1423 \mathrm{~K}$, generating hexagonal phase (Fig. 4A). This might be another reason for the very low activity of the $1423 \mathrm{~K}$ sample.

The addition of an excess amount of barium hydroxide with $\mathrm{BaTiO}_{3}: \mathrm{Rh}$ in the post-heating step was found to improve the photocatalytic activity. Even though HT synthesis was conducted in the presence of excess barium hydroxide to prevent the formation of $\mathrm{Ba}$ defects, it was found that addition of barium hydroxide in the post-heating process was important to 
enhancing photocatalytic activity. As mentioned earlier, ICP-MS analysis showed that some of the incorporated Ba species in $\mathrm{BaTiO}_{3}: \mathrm{Rh}$ were lost during the post-heating process (Table 2). Therefore, the addition of barium hydroxide in the post-heating process helped to suppress defect formation, which would be essential to enhancing photocatalytic activity of $\mathrm{BaTiO}_{3}: \mathrm{Rh}$ for $\mathrm{H}_{2}$ evolution. It indicates that post-heating with barium hydroxide resulted in the generation of $\mathrm{Ba}$-rich $\mathrm{BaTiO}_{3}: \mathrm{Rh}$, which might be more suitable for application in photocatalytic $\mathrm{H}_{2}$ evolution.

\section{Conclusions}

$\mathrm{BaTiO}_{3}: \mathrm{Rh}$ is active for photocatalytic $\mathrm{H}_{2}$ evolution from an aqueous methanol solution under visible light irradiation. In this work, we synthesized $\mathrm{BaTiO}_{3}: \mathrm{Rh}$ by a hydrothermal method followed by post-heating, and investigated the synthetic parameters. In order to enhance the photocatalytic activity, it was important to improve the compositional homogeneity and suppress the generation of $\mathrm{Ba}$ defects in $\mathrm{BaTiO}_{3}: \mathrm{Rh}$, while maintaining high crystallinity and the oxidation state of Rh(III) in the material.

\section{Experimental}

\subsection{Preparation of photocatalyst powders}

$\mathrm{TiO}_{2}$ powders were obtained from Japan Aerosil, Catalysis Society of Japan, and Kanto Chemicals. For the Rh source, $\mathrm{Rh}\left(\mathrm{NO}_{3}\right)_{3}$ (Kanto Chemicals, >80.0\%), $\mathrm{Rh}_{2} \mathrm{O}_{3}$ (Wako Pure Chemical Industries, $>98.0 \%$ ) and $\mathrm{RhCl}_{3} \cdot 3 \mathrm{H}_{2} \mathrm{O}$ (Wako Pure Chemical Industries, $>99.5 \%$ ) were employed. All chemicals were used as received.

$\mathrm{BaTiO}_{3}: \mathrm{Rh}$ was prepared by a hydrothermal method as follows. The starting materials, $\mathrm{Ba}(\mathrm{OH})_{2} \cdot 8 \mathrm{H}_{2} \mathrm{O}$ (Kanto Chemicals, $>98.0 \%$ ), $\mathrm{TiO}_{2}$, a rhodium source and $50 \mathrm{~mL}$ water, were placed in a $100 \mathrm{~mL}$ Teflon-lined stainless autoclave. The ratio of $\mathrm{Ba} / \mathrm{Ti} / \mathrm{Rh}$ was $1.0-1.1 / 0.98 / 0.02$. The autoclave was then heated $433 \mathrm{~K}$ for $42 \mathrm{~h}$. After the hydrothermal treatment, the products were naturally cooled down to room temperature. The resulting yellow precipitate was washed twice with hot water and four times with water, followed by drying at $363 \mathrm{~K}$ overnight. The powder was heated with or without addition of $5.0 \mathrm{~mol} \%$ of $\mathrm{Ba}(\mathrm{OH})_{2} \cdot 8 \mathrm{H}_{2} \mathrm{O}$ at $873-1423 \mathrm{~K}$ for $7 \mathrm{~h}$.

\subsection{Characterization of photocatalysts}

The prepared samples were studied by powder X-ray diffraction (XRD; MiniFlex 600 Rigaku; Cu K $\alpha$ ), UV-visible diffuse reflectance spectroscopy (DRS; V-565, JASCO), scanning electron microscopy (SEM; JSM-7500F, JEOL), transmission electron microscopy (TEM; H-7650, Hitachi High-Technologies), and Xray photoelectron spectroscopy (XPS; ESCA-3400, Shimadzu). The binding energies determined by XPS were corrected in reference to the $\mathrm{C} 1 \mathrm{~s}$ peak $(285.0 \mathrm{eV})$ for each sample. Elemental analysis of $\mathrm{BaTiO}_{3}: \mathrm{Rh}$ was conducted using inductively coupled plasma mass spectrometry (ICP-MS; 7700x, Agilent
Technologies). The Brunauer-Emmett-Teller (BET) surface area was measured using a BELSORP-mini (BEL Japan) at liquid nitrogen temperature (77 K).

\subsection{Photocatalytic reactions}

The procedure was essentially the same as reported previously. ${ }^{6}$ Briefly, reactions were conducted at room temperature using a top-irradiation type cell that was connected to a closed gas circulation system made of glass. $100 \mathrm{mg}$ of the as-prepared $\mathrm{BaTiO}_{3}: \mathrm{Rh}$ powder was dispersed in an aqueous methanol solution (100 mL, $10 \mathrm{vol} \%)$. A Pt cocatalyst was loaded onto $\mathrm{BaTiO}_{3}$ :Rh by an in situ photodeposition method using $\mathrm{H}_{2}$ $\mathrm{PtCl}_{6} \cdot 6 \mathrm{H}_{2} \mathrm{O}$ (Kanto Chemicals, $>98.5 \%$ ) as the precursor. After outgassing the reactant solution by a vacuum pump, Ar gas ( $c a$. $5 \mathrm{kPa}$ ) was introduced into the reaction system and the solution was irradiated under a $300 \mathrm{~W}$ Xe lamp (Cermax, PE300BF) with an output current of $20 \mathrm{~A}$. The irradiation wavelength was collected by the combination of a cold mirror (CM-1), cutoff filter (L42) and water filter $(\lambda>420 \mathrm{~nm})$. The evolved gases were analyzed by gas chromatography (Shimadzu, GC-8A with TCD detector and MS-5A column, argon carrier gas). Apparent quantum yields (AQYs) for $\mathrm{H}_{2}$ evolution were measured in the same manner, as reported previously. ${ }^{6}$

\section{Acknowledgements}

The authors thank Dr Miharu Eguchi (National Institute of Materials Science, Japan) for assistance in TEM observation. This work was supported by the PRESTO/JST program "Chemical Conversion of Light Energy" and a Grant-in-Aid for Young Scientists (A) (Project 25709078).

\section{Notes and references}

1 K. Maeda and K. Domen, J. Phys. Chem. C, 2007, 111, 78517861.

2 A. Kudo and Y. Miseki, Chem. Soc. Rev., 2009, 38, 253-278.

3 K. Maeda, J. Photochem. Photobiol., C, 2011, 12, 237-268.

4 K. Maeda, ACS Catal., 2013, 3, 1486-1503.

5 R. Konta, T. Ishii, H. Kato and A. Kudo, J. Phys. Chem. B, 2004, 108, 8992-8995.

6 K. Maeda, ACS Appl. Mater. Interfaces, 2014, 6, 2167-2173.

7 Y. Lee, T. Watanabe, T. Takata, M. Hara, M. Yoshimura and K. Domen, Bull. Chem. Soc. Jpn., 2007, 80, 423-428.

8 H. Kato, Y. Sasaki, N. Shirakura and A. Kudo, J. Mater. Chem. A, 2013, 1, 12327-12333.

9 H. Kominami, T. Matsuura, K. Iwai, B. Ohtani, S. Nishimoto and Y. Kera, Chem. Lett., 1995, 693-694.

10 H. Kominami, S. Murakami, Y. Kera and B. Ohtani, Catal. Lett., 1998, 56, 125-129.

11 K. Byrappa and T. Adschiri, Prog. Cryst. Growth Charact. Mater., 2007, 53, 117-166.

12 S. Ikeda, C. Abe, T. Torimoto and B. Ohtani, J. Photochem. Photobiol., A, 2003, 160, 61-67. 